\title{
XLIV. Examination of a gelatinous substance found in a damp meadow;-as a contribution to the knowledge of the meteors called shooting-stars
}

\section{Dr. R. Brandes}

To cite this article: Dr. R. Brandes (1828) XLIV. Examination of a gelatinous substance found in a damp meadow; - as a contribution to the knowledge of the meteors called shooting-stars, Philosophical Magazine Series 2, 3:16, 271-277, DOI: 10.1080/14786442808674641

To link to this article: http://dx.doi.org/10.1080/14786442808674641

曲 Published online: 10 Jul 2009.

Submit your article to this journal $\pi$

Џll Article views: 4

Q View related articles $\sqsubset$ 
tion of systems and technical expressions, which have received their definition beforehand, cannot be employed without the danger of perpetuating false hypotheses, and an apprehension on the part of the ignorant, that these inventions give us some power over nature not belonging to ordinary language.

The more correct mode would be to exclude from the natural method most of these terms, and to employ in their place some convertible words of looser import, as indeed M. Cuvier has to some extent done; such for instance, as group, section, division, to express those larger assemblages of approximations to assigned forms, which are rather predicated than proved; and in many cases to point them out by mere signs, such as are used in printing. Thus, for instance, the word section, or any similar word, might be employed to express the plants severally comprehended in the order Graminece, the class Composita, and the division Monocotyledones; and where the characters are less definite, the plants pointed at might be assembled under a simple asterisk.

One chief recommendation of the natural system over the artificial, is the liberty which it leaves to the mind. The one shuts it in to the narrowest scope of observation, while the other suffers it to range in search of all the properties belonging to created beings; their functions, their structure, relations and resemblances, affinities and analogies. It is speculative and general truth that the natural system enables us to pursue; and this will never submit to be bound by any fetters which the art of man can invent. Books after all are but a rude mode of holding knowledge together; and language but an imperfect vehicle to convey with precision the just relations of things. At best it bears the image of the earthy, while things themselves bear the image of the heavenly.

XLIV. Examination of a gelatinous Substance found in a damp Meadow; - as a Contribution to the Knowledge of the Meteors called Shooting-Stars. By Dr. R. Brandes*.

MY friend Dr. Buchner communicated some time ago (in II Kastner's Archiv.'v. 182), a treatise on the substance of the meteors called Shooting-Stars, which Kastner has designated by the name of star-jelly. This substance, found in a damp meadow, was of a gelatinous appearance, and was supposed by Dr. Schultes to be Tremella nostoc. M. Buchner, however, having examined it, was of a different opinion, not having been able to discover in it any trace of an organic tissue.

* From Schweigger's Jahrbuch der Chemie, N. R. Band xix. p. 389. 


\section{Dr. Brandes's Examination of a gelatinous Substance}

Indeed he does not decide whether its origin was terrestrial or not; yet he asserts that this substance could be neither a plant nor an animal, (at least not an entire one, ) but perhaps the produce of an animal, an excretion resembling gum, mucus, \&c.; and although he does not deny the possibility of such a body having descended from the atmosphere, he does not think it very probable. Nay, he does not much object even to the comparison of this slimy substance with the manna of the Israelites, which fell from heaven;- he thinks at least that this slimy mass might be as nourishing as oysters. However inclined I may feel to agree with my respected friend on the first two points; viz. that this mass might originate from the excretion of an animal, or a gelatinous meteor, the idea of comparing it with the manna of the Israelites seems to me untenable, there being too great a difference between both the nature of the substances and the places in which they have been found, I was much inclined to ascribe to the substance in question an atmospheric origin, in consequence of the want of organic structure, which M. Buchner ascribes to the mass he examined; in consequence also of the account given by R. Graves of a fiery meteor which had fallen in Massachusetts, in the United States, in a spot where the following morning a gelatinous substance was found ${ }^{*}$; in consequence, moreover, of my own observations on the existence of atoms of azotized substances in the atmosphere, at least in rain-water, (Jahrb. 1826, iii. 253); and ultimately from the account frequently repeated to me by a soldier of the contingent of Lippe, who had fought in the Peninsula, of his having frequently noticed in Spain, while on duty during cold nights, stars to shoot, and perceived in the morning in damp places, where he thought them to have fallen, white gelatinous masses, which were soon decomposed; an opinion which I also mentioned in my treatise on Rain-water.

M. Schwabe, an apothecary at Dessau, published some time after a treatise on the same subject (Kastner's Archiv. vii. p. 428), on his having had an opportunity of examining a substance which had been found in a damp meadow, which was likewise gelatinous and of a green colour. Mr. S. recognised this mass distinctly as Nostoc commune Vauch. (Tremella nostoc, Linn.), having discovered in it through the microscope the structure of this singular nostoc. As this mass agreed not only in its external form and place of discovery with that of Buchner, but also in its chemical composition, Mr. S. thought himself justified in assuming that both this substance and that

* Gilbert's Annalen, Ixxi. 314. 
of Buchner were of the same nature; since, owing to its peculiar texture, Mr. B. might have overlooked its organic structure. But on comparing more closely the descriptions given by the two naturalists of the substances observed by them, we discover several other differences, besides the one that Mr. Schwabe discovered,-a distinct organic structure; while Mr. Buchner saw none. The substance examined by Mr. S. was of a greenish colour; that of $\mathrm{Mr}$. B. white, like swelled tragacanth. The former on being burned emitted, not an animal smell, but one quite peculiar, resembling burning conferva, rivularice, and chetophore, and yielded a shining coal, which preserved the skinny form of the pieces employed; and being reduced to ashes, left a residuum of silica, with carbonate, muriate, and sulphate of potash, with traces of phosphate of lime and oxide of iron; but Buchner's substance, on being heated, swelled considerably, diffusing at the same time a strong animal smoke; caught fire at last, and left a coal that could not be reduced to ashes, and which contained carbonate of soda and phosphate of lime. However similar Mr. S. may consider his substance to that of Mr. B., the facts here stated seem to invalidate his conclusion as to their identity. I feel, therefore, great pleasure in being able to communicate an examination which $I$ had an opportunity of making last autumn, and which may perhaps throw some light on the point in question.

A friend and fellow-townsman of mine, who has a large meadow near our city, which, lying in the lower part of our salt-valley, has been drained in a slight degree by dint of great labour, and the grass in it improved by the application of salt and ashes, for manure, found in this very meadow a gelatinous substance, and was told by a labourer that he had frequently seen similar ones there; a circumstance which had escaped my friend and me, though both often passing through it.

My friend having brought me this substance for examination, my mind immediately reverted to that examined by Mr.Buchner; and perceiving even outwardly several differences between them, I undertook a close examination of it, as follows.

The substance was of a very clear white colour, representing a strongly swelled mass, which $\mathrm{Mr}$. B. very properly compares to swelled tragacanth; its bulk might be about $2 \frac{1}{2}$ cubic inches. On a closer view, I perceived that in several places it was covered with a very fine white skin, which seemed to have burst in the centre only; in such parts the inside had protruded in the shape of a very bulky gelatinous mass. The

New Series. Vol. 3. No. 16. April 1828. $2 \mathrm{~N}$ bursting 


\section{Dr. Brandes's Examination of a gelatinous Substance}

bursting of the skin had undoubtedly been produced by the swelling of the mass on account of the moisture it had absorbed from the meadow, a tension which the thin membranous covering could not resist. In such parts too the membrane was so concealed by the jelly that it could scarcely be perceived. Nor had the jelly here any distinct form, or any traces of organization. But wherever the mass had remained entire, and although swelled was still inclosed, it showed a vermicular appearance of the thickness of a quill and thicker; whilst in those places where the membrane had burst, the inside projected in lumps of three-quarters of an inch in thickness. This vermicular appearance presented several small slightly indented divisions, and had entirely the figure of an intestine; the back was marked by a tender vessel of a darkish-brown colour, which spread with fine veins towards the front, losing themselves about the middle in small blackish points. By this vessel the back of the mass was entirely contracted, and much extended towards the surface, just like an intestine.

In a dry place the substance gradually shrunk, soon lost its white colour, turned to a brownish yellow hue, became very tough, so that it could be drawn into threads like glue, and dried at last into a horny mass.

Burned in a crucible of platinum it swelled, became gradually black, emitted a strong animal smell, like singed wool, and left 1.2 of grayish white ashes, which were scarcely affected by water for some time, but at length gave a slightly alkaline solution. In nitric acid the ashes were completely dissolved, and ammonia gave a precipitate of phosphate of lime.

Twenty grains of this substance were desiccated on a waterbath. It became hard and tough; and its weight was reduced to four grains. Moistened with water, it in a short time re-assumed its former size and white colour.

One hundred grains of the substance were boiled in three ounces of water; by this it swelled into a tremulous jelly, which was so bulky that it had thickened almost all the water; for the whole being deposited on a loose clean linen cloth, it congealed upon it; and after several hours but little of the liquid had oozed out, which was rendered turbid by protonitrate of mercury and acetate of lead, but not by superacetate of lead. A little of the substance was shaken with alcohol; this acted but little, but separated from it some of the water, and on its bulk being diminished, it likewise lost its transparency.

A solution of ammonia acted but slightly, whether in the cold or by heat; but a solution of caustic potash affected it perceptibly even while cold, and entirely absorbed it when 
heated : neutralized by any acid, the substance was again precipitated. The sulphuric, nitric, and muriatic acids also acted upon it while cold, and entirely dissolved it by heat. The nitric acid turned somewhat yellow, the sulphuric acid brown; the muriatic acid remained colourless.

From these experiments it is evident that this substance did not resemble albumen, but essentially agreed with jelly, and resembled the slime of springs. It consisted of

Gelatinous substance.............................. 18:8

Animal ditto .............................. traces

Phosphate of lime and phosphate of soda, with $\} 1.2$

Water .......................................... 80.0

$100 \cdot 0$

What now is the origin of this substance?

The evident existence of an organic structure will not allow any opinion of its being of an atmospheric formation, but shows on the contrary that its origin must be terrestrial and of an animal kind. Its striking resemblance to an intestine, led me at first to suppose that it might have been the intestine of a bird; but its containing a smooth jelly, and being inclosed in so fine a membrane, compared with the tougher skin of any intestine, which could not have swelled to the degree mentioned, the want of the usual contents of an intestine, \&c. left ultimately no room for such a supposition. But the chemical resemblance of this substance to the spawn of frogs, led me to the idea of its being perhaps the spawn of some animal. It could not be that of a frog, but it might be the swelled spawn of a snail, such as are frequently found in damp meadows; as the Limax rufus, agrestis, stagnalis, \&c. I compared the descriptions given in this respect in Cuvier's Comparative Anatomy; in Oken's Natural History, iii. chap. i. p. 309 ; in the same author's Natural History for Schools, p. 668 ; in Goldfuss' Hanbuch der Zoologie, i. p. 661, and other works; -in all of which, however, I found little information respecting the object of my research ; viz. the spawn of snails. Oken, in his Natural History for Schools, however, remarks, when speaking of $L i-$ max stagnalis, that " its spawn was a small gelatinous cylinder, of one inch in length and one line in thickness, containing a dozen small yellow eggs; that these rows of eggs generally adhere to some aquatic plants, and at the end of a fortnight or three weeks the young snail crept out of it." Oken further mentions in his Natural History, concerning the limaces: "The excremental canal of the sexual bladder is short, ends in the vagina close to the ovarium, much longer as it should 
276 Dr. Brandes's Examination of a gelatinous Substance, \&c.

seem, in proportion to the penis, and the ovarium connects with it before it enters the vagina. There is, therefore, no doubt that this bladder forms a portion of the female parts, and furnishes perhaps the gelatinous substance for the eggs, especially as this bladder is found in all snails. Their contents, however is solid, soft like pomatum, and red-brown, which has led to the erroneous supposition of its being purple." (Compare also Cuvier on the same subject.) Although the egg-sticks of the limax, as mentioned, are very small, it is yet possible to suppose our substance to have been the spawn of a Limax rufus, or some other species, since its great bulk chiefly arose from water, - a reason too why its solid contents, compared with its volume, were so small, and those of the water so great; and I was enabled, as we have seen in the experiment with boiling water, to swell it to its actual extent. 'This supposition was further confirmed, on my finding in a portion of the substance which I had placed in a small cup before the window of my study for a few days, a little naked snail (limax) of about a quarter of an inch long. I think, therefore, I may positively assert that the white gelatinous substances which are occasionally found in damp meadows, and frequently pronounced to be the substance of shooting-stars, are not of atmospheric origin, but consist of the spawn of the above-mentioned snails, which, although small in its natural state, and therefore remaining unobserved, assumes, in damp places, by absorbing water, the large bulk and white gelatinous appearance, necessarily attracting the attention of persons who find them in their way; and finally, that its being found only in damp places is owing to the very nature of this spawn.

I doubt whether the real substance of a shooting-star has ever been found. Whoever has observed these meteors, must be convinced that one could not so readily notice the spot where they seem to fall in the darkness of night, as to be able to find out the supposed substance, and as it were be able to say that he has a fallen star in his hand. Before this can be clearly shown, it may yet have to be proved whether any opinion can be formed as to the nature of shooting-stars. Even the observation of the above-mentioned American meteor seems subject to doubt; and it is still a question whether the produce of a fiery meteor could be a gelatinous mass?

Our knowledge of meteors is indeed much increased by the inquiries of Professor Brandes of Breslaw; but still the nature of the substance seems to be enveloped in doubt.

It now only remains for me to consider the apparent differences which seem to exist between the observations of Messis. Buchner and Schwabe, and my own; which may be satisfactorily 
satisfactorily done in consequence of the precision with which those gentlemen have written their accounts.

The substances they have respectively examined offer, as I have stated above, qualities so different in their nature, as to ascribe to each a different origin; so that I cannot agree with Mr. S. in supposing the substance examined by him to be of the same kind as Mr. B.'s, while I readily admit that the substance he has investigated was a real tremella. Mr. B.'s substance, on the contrary, fully agrees with that examined by me. Their chemical contents are quite the same; and the only essential difference between them seems to be, that the substance examined by him no longer exhibited any organic structure; whilst that observed by me still bore the evident traces of an animal production. But if we consider that this snail-spawn had lost all appearance of organic structure wherever the membrane had burst, and especially when it was much swelled with water, I suppose that Mr. B. found this substance so swelled, that it had burst the membrane in every part, so as to cover and obliterate the organic structure entirely. That the mass examined by $\mathrm{Mr}$. B. was actually very much swelled, appears from the fact, that he found only 40.4 of solid substance; whilst the one examined by me still had $20^{\circ} 0$. If then the identity of the two cannot be doubted, we must at once ascribe the same origin to both,- - that of being the spawn of a snail.-Thus I think I have explained the nature of the substance called starjelly, and have had the satisfaction of reconciling the differences between the observations of Messrs. B. and S.; having shown that the observations of both these meritorious naturalists were correct, but that the substances were entirely different in their nature.

XLV. Description of a Percussion Rifle, igniting by a Spring instead of a Lock. By Lieut.-Col. MinLER, F.R.S.**

T $\mathrm{HE}$ stock of this rifle is made either of iron or bronzet, hollow in the centre, and the barrel is made to screw into it at the breech. The spring acts horizontally, and is screwed to a plate, fixed to the left side of the small of the stock. A cross piece is attached to the fore part of the spring, which passes through the stock behind the breech, and projects a little on the left side. In the cross piece there is a notch, and a button at the end of it; - the trigger moves upon a pivot in the upper part of the stock, and is pressed forward by a spring behind it. The piece is cocked by grasping the small of the

* Communicated by the Author.

$\dagger$ As manufactured by Nock. stock 